\title{
Comparative analysis reveals conservation in genome organization among intestinal Cryptosporidium species and sequence divergence in potential secreted pathogenesis determinants among major human-infecting species
}

\author{
Zhixiao Xu', Yagiong Guo ${ }^{2}$, Dawn M. Roellig ${ }^{3}$, Yaoyu Feng ${ }^{1,2^{*}}$ and Lihua Xiao ${ }^{2^{*}}$
}

\begin{abstract}
Background: Cryptosporidiosis is a major cause of gastrointestinal diseases in humans and other vertebrates. Previous analyses of invasion-related proteins revealed that Cryptosporidium parvum, Cryptosporidium hominis, and Cryptosporidium ubiquitum mainly differed in copy numbers of secreted MEDLE proteins and insulinaselike proteases and sequences of mucin-type glycoproteins. Recently, Cryptosporidium chipmunk genotype I was identified as a novel zoonotic pathogen in humans. In this study, we sequenced its genome and conducted a comparative genomic analysis.

Results: The genome of Cryptosporidium chipmunk genotype I has gene content and organization similar to C. parvum and other intestinal Cryptosporidium species sequenced to date. A total of 3783 putative proteinencoding genes were identified in the genome, 3525 of which are shared by Cryptosporidium chipmunk genotype I and three major human-pathogenic Cryptosporidium species, C. parvum, C. hominis, and Cryptosporidium meleagridis. The metabolic pathways are almost identical among these four Cryptosporidium species. Compared with C. parvum, a major reduction in gene content in Cryptosporidium chipmunk genotype I is in the number of telomeric genes encoding MEDLE proteins (two instead of six) and insulinase-like proteases (one instead of two). Highly polymorphic genes between the two species are mostly subtelomeric ones encoding secretory proteins, most of which have higher $\mathrm{dN} / \mathrm{dS}$ ratios and half are members of multiple gene families. In particular, two subtelomeric $\mathrm{ABC}$ transporters are under strong positive selection.

(Continued on next page)
\end{abstract}

\footnotetext{
* Correspondence: yyfeng@scau.edu.cn; Ixiao@scau.edu.cn

'State Key Laboratory of Bioreactor Engineering, School of Resources and Environmental Engineering, East China University of Science and Technology, Shanghai 200237, China

${ }^{2}$ Key Laboratory of Zoonosis of Ministry of Agriculture, College of Veterinary

Medicine, South China Agricultural University, Guangzhou 510642, China

Full list of author information is available at the end of the article
}

(c) The Author(s). 2019 Open Access This article is distributed under the terms of the Creative Commons Attribution 4.0 International License (http://creativecommons.org/licenses/by/4.0/), which permits unrestricted use, distribution, and reproduction in any medium, provided you give appropriate credit to the original author(s) and the source, provide a link to the Creative Commons license, and indicate if changes were made. The Creative Commons Public Domain Dedication waiver (http://creativecommons.org/publicdomain/zero/1.0/) applies to the data made available in this article, unless otherwise stated. 


\begin{abstract}
(Continued from previous page)
Conclusions: Cryptosporidium chipmunk genotype I possesses genome organization, gene content, metabolic pathways and invasion-related proteins similar to the common human-pathogenic Cryptosporidium species, reaffirming its human-pathogenic nature. The loss of some subtelomeric genes encoding insulinase-like proteases and secreted MEDLE proteins and high sequence divergence in secreted pathogenesis determinants could contribute to the biological differences among human-pathogenic Cryptosporidium species.
\end{abstract}

Keywords: Cryptosporidium chipmunk genotype I, Comparative genomics, MEDLE family proteins, Insulinase-like proteases, ABC transporters

\section{Background}

Cryptosporidium spp. are important apicomplexan parasites, causing moderate to severe diarrhea in humans and various animals. Currently, there are near 40 named Cryptosporidium species and about the same number of genotypes with unknown species status [1]. Among them, approximately 20 have been found in humans [2]. However, Cryptosporidium parvum and Cryptosporidium hominis are two major species infecting humans. Other species, including Cryptosporidium meleagridis, Cryptosporidium felis, Cryptosporidium canis, Cryptosporidium ubiquitum, Cryptosporidium cuniculus, Cryptosporidium viatorum, and Cryptosporidium muris, are less common [1].

Cryptosporidium species differ in host range and public health significance [3]. Among the human-pathogenic species, C. parvum has the broadest host range. In addition to humans, it infects ruminants, equine animals, rodents, and some other animals. In contrast, $C$. hominis is mostly restricted to humans, nonhuman primates, and equine animals [1]. As the third most prevalent species infecting humans, C. meleagridis has been reported in both mammals and birds [2, 4, 5]. Another Cryptosporidium species, C. ubiquitum, also has a broad host range, being commonly detected in small ruminants, rodents, in addition to humans [6, 7]. Cryptosporidium chipmunk genotype I, which was initially found in several species of rodents, is a novel zoonotic pathogen, having been reported in humans recently [8,9]. It is one of the three major zoonotic Cryptosporidium species in humans in rural United States [10].

Results of comparative genomics analysis suggest that members of several secreted protein families, such as MEDLE proteins, insulinase-like proteases, and mucintype glycoproteins, are potential determinants for differences in host range among Cryptosporidium species [11, 12]. The difference in the number of MEDLE genes among Cryptosporidium species or C. parvum subtype families (IIa in bovines and IId in small ruminants) indicates that MEDLE proteins could contribute to differences in host specificity $[11,13]$. Insulinase-like proteases are secreted proteases, being involved in processing invasion-related proteins in apicomplexans or modifying host cell proteins [14]. Mucin-type glycoproteins are known to be involved in the attachment and invasion of Cryptosporidium spp. [15]. Compared with C. parvum, a reduction in the numbers of genes encoding the MEDLE family secreted proteins and insulinase-like proteases was seen in the $3^{\prime}$ subtelomeric regions of chromosomes 5 and 6 of the C. hominis genome [11]. The orthologous regions encoding subtelomeric insulinases and MEDLE proteins are entirely absent in the genomes of $C$. ubiquitum and gastric species Cryptosporidium andersoni [12]. In addition to the gene losses, genetically related Cryptosporidium species differ significantly in sequences of mucin-type glycoproteins [11, 12]. As intestinal and gastric Cryptosporidium species differ significantly in the numbers and sequences of genes encoding mucin-type glycoproteins and insulinase-like proteases, these proteins and other secreted pathogenesis determinants (SPDs) potentially play an important role in tissue tropism also [12].

Although the genomes of several Cryptosporidium species have been sequenced recently, we still have very limited knowledge of genome evolution among Cryptosporidium spp. [16, 17]. In this study, we have sequenced the genome of Cryptosporidium chipmunk genotype I and conducted a comparative genomic analysis of eight Cryptosporidium species that have been sequenced thus far $[11,12,18-20]$.

\section{Results}

\section{Genome features}

We generated 6.8 million 250-bp paired-end reads from one Cryptosporidium chipmunk genotype I isolate 37,763 from a naturally infected person in the United States by Illumina sequencing. After filtering out contigs from contaminants among the 298 initial contigs generated using the CLC Genomics Workbench, we assembled a Cryptosporidium genome of $9.05 \mathrm{Mb}$ in 50 contigs (without any scaffolding during the processing), with an estimated 188-fold coverage and an N50 of $320,570 \mathrm{bp}$. We combined gene prediction results obtained from Augustus, Geneid, and Genemark, leading to the identification of 3783 protein-encoding genes. At 
the genome level, Cryptosporidium chipmunk genotype I has high nucleotide and amino acid sequence identity to C. parvum ( 82.25 and $83.49 \%$, respectively), C. hominis (82.48 and $83.99 \%$, respectively), and C. meleagridis (81.22 and $81.68 \%$, respectively; Table 1 ). Among the eight Cryptosporidium species with whole genome sequence data, Cryptosporidium chipmunk genotype I has the highest GC content in the overall genome (32.0\%) and coding regions (33.6\%). The genome of Cryptosporidium chipmunk genotype I has near complete sequence synteny with that of $C$. parvum and $C$. ubiquitum (Fig. 1a), with a rearrangement of $\sim 126 \mathrm{~kb}$ between Cryptosporidium chipmunk genotype I and C. parvum. The $5^{\prime}$ subtelomeric region of chromosome 6 in Cryptosporidium chipmunk genotype I, which contains 52 genes, is translocated with the $5^{\prime}$ subtelomeric region of chromosome 8 containing 53 genes (cgd8_10 cgd8_530) in C. parvum. This rearrangement was observed in both assemblies produced by the CLC Genomics Workbench and the SPAdes assembler. Advanced sequencing using the PacBio technology is needed to confirm the existence of this genome rearrangement. Lower synteny was seen with genomes of $C$. baileyi and $C$. andersoni. Cryptosporidium chipmunk genotype I shares almost the same gene density and number of tRNA genes with other Cryptosporidium spp. It, however, has gene content slightly lower than C. parvum and C. hominis, but similar to $C$. meleagridis, $C$. ubiquitum, and $C$. baileyi (Table 1).

Orthology delineation identified only a small number of species-specific genes among eight Cryptosporidium spp. Approximately 3525 genes are shared by C. parvum, C. hominis, C. meleagridis, and Cryptosporidium chipmunk genotype I (Fig. 1b). There are only three Cryptosporidium chipmunk genotype I-specific genes. One of them was identified as an insulinase-like protease, but the functions of other two genes are unknown. Phylogenetic analysis of amino acid sequences from 100 orthologous genes supported the close relatedness of Cryptosporidium chipmunk genotype I to these human-pathogenic Cryptosporidium species (Fig. 2a).

Multiple gene families are present in Cryptosporidium chipmunk genotype I as well as other Cryptosporidium species. Protein architecture network analysis of Cryptosporidium chipmunk genotype I, C. parvum, and $C$. meleagridis revealed the existence of several clusters (Fig. 3a). Two of the major clusters (1 and 2 ) in the network consisted of protein kinases and insulinase-like peptidases of the three Cryptosporidium species. There are 75,79 , and 78 genes encoding protein kinases in Cryptosporidium chipmunk genotype I, C. parvum, and C. meleagridis, respectively. C. parvum possesses 23

Table 1 Genomic features of Cryptosporidium chipmunk genotype I in comparison with some other Cryptosporidium spp

\begin{tabular}{|c|c|c|c|c|c|c|c|c|}
\hline & $\begin{array}{l}\text { Cryptosporidium } \\
\text { chipmunk genotype I }\end{array}$ & $\begin{array}{l}\text { C. } \\
\text { parvum }\end{array}$ & $\begin{array}{l}\text { C. hominis } \\
\text { UdeA01 }\end{array}$ & $\begin{array}{l}\text { C. } \\
\text { meleagridis }\end{array}$ & $\begin{array}{l}\text { C. } \\
\text { ubiquitum }\end{array}$ & $\begin{array}{l}\text { C. } \\
\text { baileyi }\end{array}$ & $\begin{array}{l}\text { C. } \\
\text { andersoni }\end{array}$ & $\begin{array}{l}C . \\
\text { muris }\end{array}$ \\
\hline Total length (Mb) & 9.05 & 9.1 & 9.06 & 8.97 & 8.97 & 8.5 & 9.09 & 9.21 \\
\hline No. of super contigs & 50 & 8 & 97 & 57 & 27 & 153 & 135 & 45 \\
\hline GC content (\%) & 32 & 30.3 & 30.1 & 31 & 30.8 & 24.3 & 28.5 & 28.4 \\
\hline $\begin{array}{l}\text { Nucleotide sequence identity } \\
(\%)\end{array}$ & - & 82.25 & 82.48 & 81.22 & 78.65 & 46.08 & 26.44 & 26.89 \\
\hline Number of genes & 3783 & 3805 & 3819 & 3782 & 3767 & 3728 & 3905 & 3937 \\
\hline Total length of CDS (Mb) & 6.94 & 6.83 & 6.81 & 6.91 & 6.94 & 6.69 & 6.86 & 6.93 \\
\hline GC content in CDS (\%) & 33.6 & 31.9 & 31.8 & 32.4 & 33 & 25.6 & 30.1 & 30 \\
\hline $\begin{array}{l}\text { Amino acid sequence identity } \\
\text { (\%) }\end{array}$ & - & 83.49 & 83.99 & 81.68 & 79.04 & 58.89 & 47.03 & 47.22 \\
\hline $\begin{array}{l}\text { GC content at } 3^{\text {rd }} \text { position in } \\
\text { codons }(\%)\end{array}$ & 26.9 & 22.5 & 23.5 & 24.1 & 24.5 & 12.6 & 18.1 & 17.8 \\
\hline Gene density (gene/Mb) & 418 & 418.1 & 421.5 & 421.6 & 420 & 438.6 & 429.6 & 427.5 \\
\hline Percent coding (\%) & 76.7 & 75 & 75.2 & 77 & 77.4 & 78.7 & 75.5 & 75.2 \\
\hline No. of genes with intron & 515 & 163 & 417 & 506 & 758 & 763 & 832 & 798 \\
\hline Genes with intron (\%) & 13.6 & 4.2 & 10.9 & 13.4 & 20.1 & 20.5 & 21.3 & 20.3 \\
\hline No. of tRNA & 45 & 45 & 45 & 45 & 45 & 46 & 44 & 45 \\
\hline No. of tRNA ${ }^{\text {met }}$ & 2 & 2 & 2 & 2 & 2 & 2 & 2 & 2 \\
\hline Proteins with signal peptide & 396 & 397 & 391 & 397 & 399 & 344 & 309 & 323 \\
\hline $\begin{array}{l}\text { Proteins with transmembrane } \\
\text { domain }\end{array}$ & 793 & 832 & 817 & 805 & 772 & 813 & 839 & 836 \\
\hline Proteins with GPI anchor & 57 & 63 & 54 & 55 & 50 & 57 & 47 & 52 \\
\hline
\end{tabular}



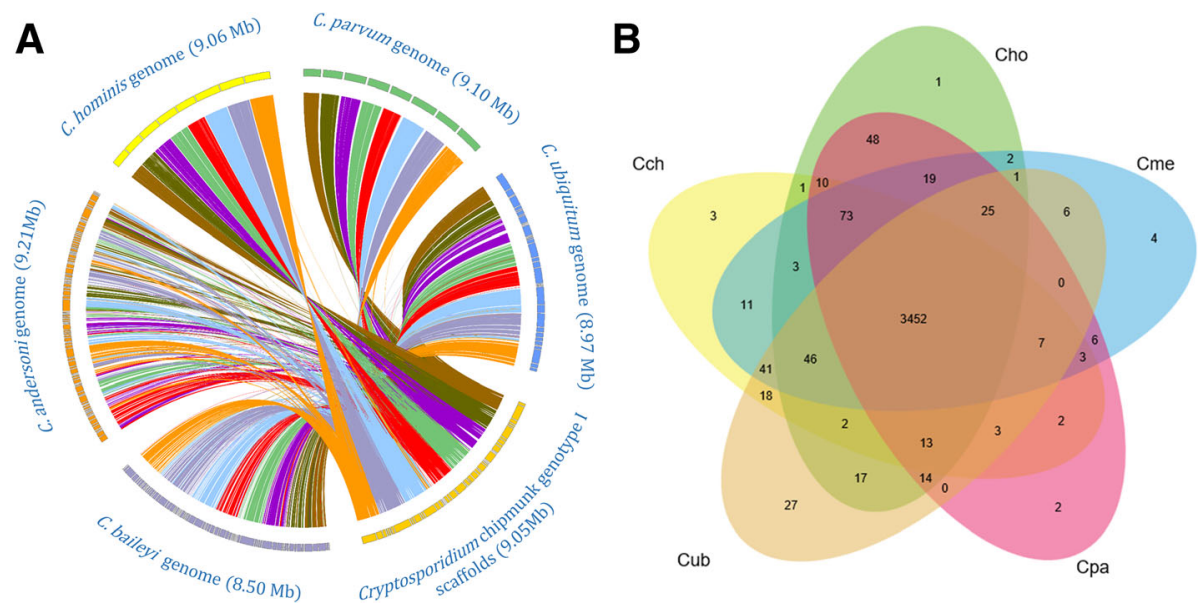

Fig. 1 Syntenic relationship and shared orthologous genes among Cryptosporidium spp. a Syntenic relationship in gene organization among genomes of Cryptosporidium chipmunk genotype I, Cryptosporidium parvum, C. hominis, C. ubiquitum, C. baileyi, and C. andersoni. Syntenic blocks (regions with orthologous genes) are connected with lines, with the colors representing 8 chromosomes of $C$. parvum. $\mathbf{b}$ Venn diagram of orthologous genes shared by five Cryptosporidium spp. Abbreviations of taxa: Cryptosporidium parvum IOWA (Cpa); C. hominis Ude (Cho); C. meleagridis (Cme); Cryptosporidium chipmunk genotype I (Cch); C. ubiquitum (Cub)

\section{A}

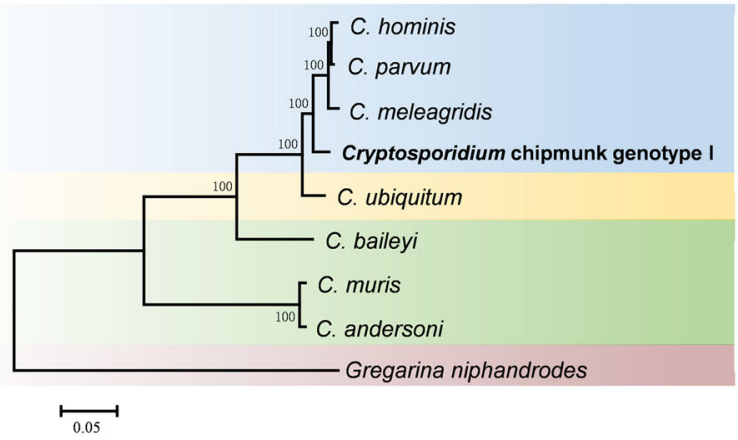

C

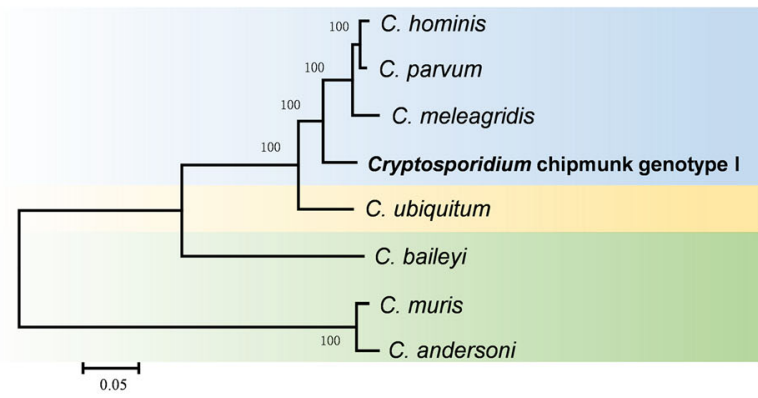

B
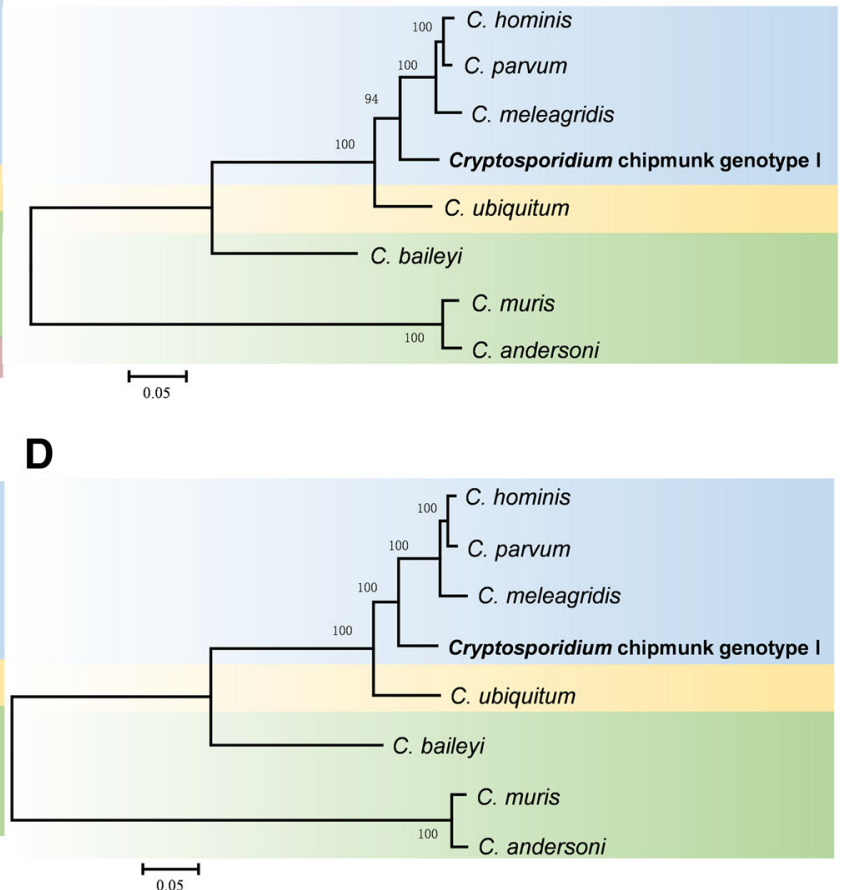

Fig. 2 Phylogenetic relationship of Cryptosporidium spp. a Phylogenetic relationship of Cryptosporidium spp. based on maximum likelihood analysis of sequences of 100 shared proteins. b Phylogenetic relationship of Cryptosporidium spp. based on maximum likelihood analysis of TRAP sequences. $\mathbf{c}$ Phylogenetic relationship of Cryptosporidium spp. based on maximum likelihood analysis of mucin-type glycoproteins. $\mathbf{d}$ Phylogenetic relationship of Cryptosporidium spp. based on maximum likelihood analysis of insulinase-like proteases 

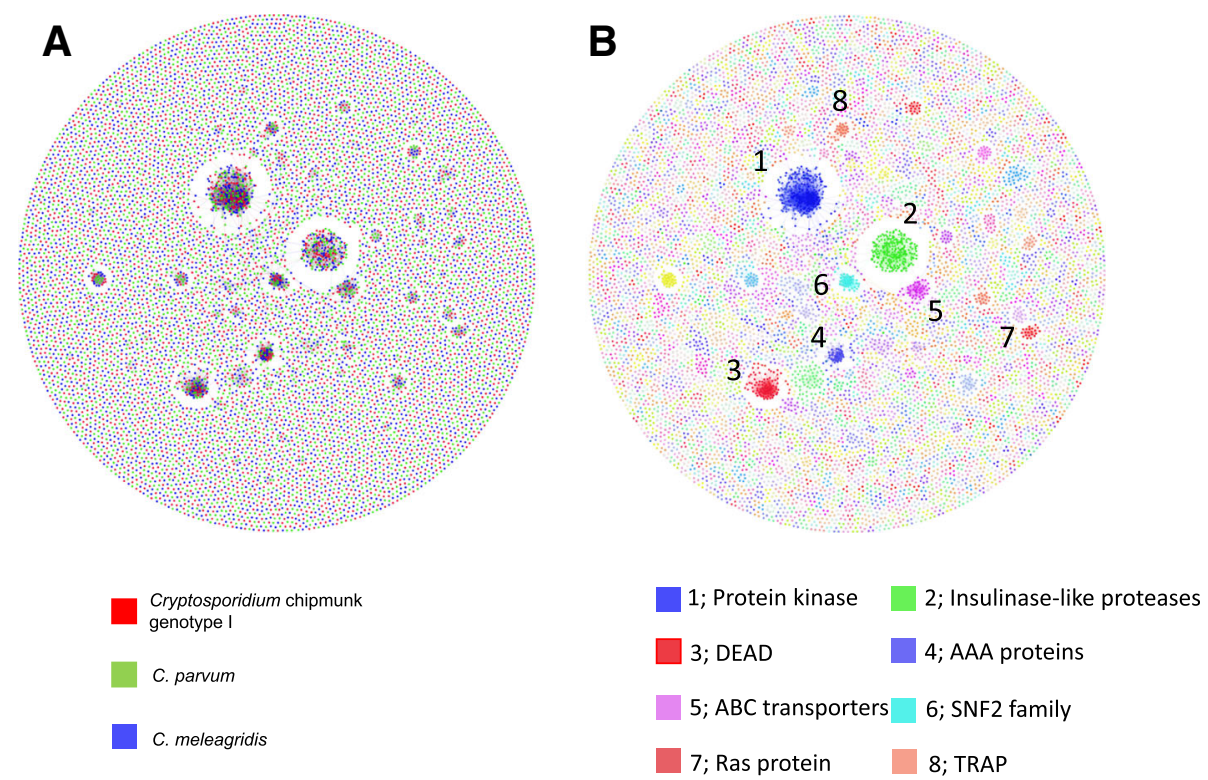

Fig. 3 Protein architecture network based on sequence similarity of all proteins in proteomes of Cryptosporidium chipmunk genotype I, Cryptosporidium parvum, and Cryptosporidium meleagridis. a Proteins of Cryptosporidium chipmunk genotype I, C. parvum, and C. meleagridis, represented by the colors red, green, and blue, respectively. $\mathbf{b}$ Identity of major clusters in the Cryptosporidium proteome

genes encoding insulinase-like peptidases, while 22 genes encoding insulinase-like peptidases was detected Cryptosporidium chipmunk genotype I and C. meleagridis. Members of helicases such as DEAD and SNF2 formed Clusters 3 and 6, which are involved in unwinding nucleic acids and RNA metabolism. The three Cryptosporidium species possess the same number of genes encoding DEAD (39 genes) and SNF2 (16 genes). ATPases associated with diverse cellular activities (AAA) and ATP-binding cassette $(\mathrm{ABC})$ transporters formed Cluster 4 and 5. We found 21 genes encoding ABC transporters in all three species. Compared with $C$. parvum and C. meleagridis, one gene encoding AAA proteins was lost in Cryptosporidium chipmunk genotype I (24 AAA proteins). In addition, the Ras proteins, which are involved in- intracellular signaling, formed Cluster 7. Furthermore, the 12 thrombospondin-related adhesive proteins (TRAPs), which are presumably microneme proteins present in all three Cryptosporidium species under analysis [21, 22], are included in Cluster 8 (Fig. 3b).

\section{Characteristics of metabolism in Cryptosporidium chipmunk genotype I \\ Carbohydrate metabolism}

Similar to other intestinal Cryptosporidium spp., Cryptosporidium chipmunk genotype I lacks genes encoding core enzymes of the tricarboxylic acid (TCA) cycle, but possesses enzymes for the synthesis of pyruvate from glucose in glycolysis. Furthermore, a gene for a phosphoenolpyruvate carboxylase (Cch_34.2917) was detected in Cryptosporidium chipmunk genotype I, suggesting that this parasite can convert phosphoenolpyruvate (PEP) to oxaloacetate (OAA).

Like other Cryptosporidium spp., Cryptosporidium chipmunk genotype I lacks genes encoding enzymes for de novo isoprenoid biosynthesis. Two genes encoding farnesyl diphosphate (FPP) synthase (Cch_19.1677) and polyprenyl synthase (Cch_17.1265) were detected in Cryptosporidium chipmunk genotype I. These two genes were shown transcribed in C. parvum in vitro [23], but are absent in C. ubiquitum [12].

\section{Electron transport chain}

A progressive reduction in the electron transport chain was reported in Cryptosporidium spp. [12]. Most intestinal Cryptosporidium spp. have an alternative oxidase (AOX) and a reduced conventional electron transport system, except for C. ubiquitum, which does not have them and the AOX. Unlike C. ubiquitum, Cryptosporidium chipmunk genotype $\mathrm{I}$ and the three major human-pathogenic species possess all enzymes and proteins involved in the ubiquinone biosynthesis (Fig. 4).

The number of mitochondrial carrier proteins in Cryptosporidium spp. is in agreement with the nature of the electron transport system. As reported previously [12], gastric Cryptosporidium spp. have more mitochondrial carrier proteins than intestinal Cryptosporidium spp. (Table 3). Among the latter, eight mitochondrial carrier proteins were detected in Cryptosporidium chipmunk genotype I and $C$. meleagridis, compared with nine in C. parvum and C. hominis and six in C. ubiquitum and C. baileyi, which also does not have the AOX 


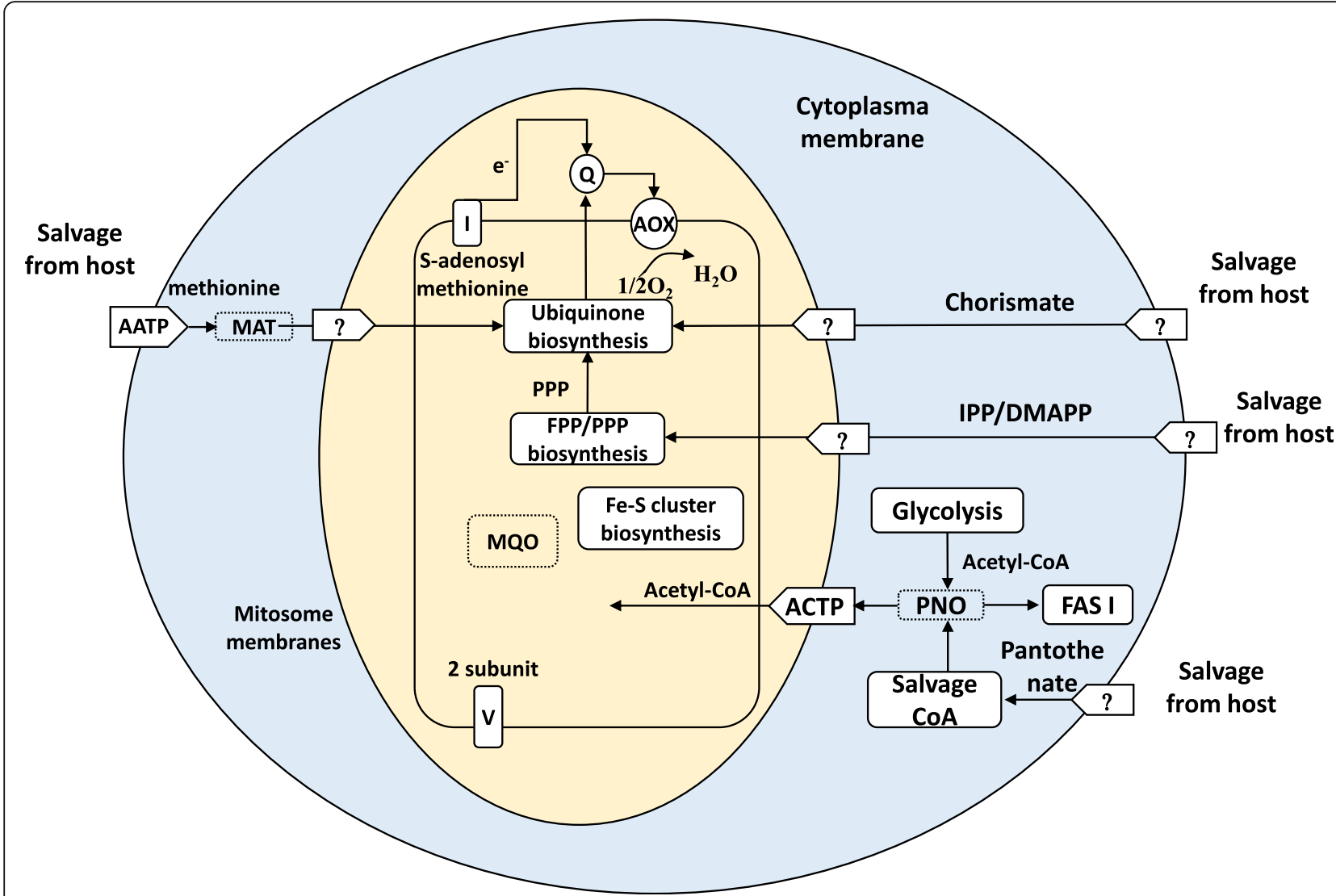

Fig. 4 Mitochondrial metabolism of Cryptosporidium chipmunk genotype I. Abbreviation of enzymes: AOX: alternative oxidase; PNO: pyruvate:NADP(+) oxidoreductase; MAT: methionine adenosyl transferase; MQO: malate:quinone oxidoreductase. Abbreviation of metabolites: Q: ubiquinone (coenzyme Q); CoA: coenzyme A; IPP: isopentenyl diphosphate; DMAPP: dimethylallyl diphosphate; FPP: farnesyl diphosphate; PPP: polyprenyl diphosphate. Abbreviation of transporter proteins: AATP: amino acids transporter protein; ACTP: acetyl-CoA transporter protein

(Table 3). These data indicate that the mitosome metabolic capability in Cryptosporidium chipmunk genotype I is similar to that in the three major human-pathogenic Cryptosporidium species.

\section{Nucleotide metabolism}

All Cryptosporidium spp. cannot synthesize purine rings or pyrimidines de novo (Table 2). Instead, they must salvage these nucleotides from the host via the nucleoside transporter (Table 3). However, the enzymes involved in the inter-conversion of purines and pyrimidines are different among Cryptosporidium species. The gene encoding the guanosine monophosphate (GMP) synthase (cgd5_4520 in C. parvum) is lost in Cryptosporidium chipmunk genotype I, indicating that Cryptosporidium chipmunk genotype I cannot convert xanthosine 5 '-phosphate (XMP) to GMP. Furthermore, the last gene (cgd1_3860) in chromosome 1 of C. parvum, which encodes a deoxyuridine triphosphate (dUTP) diphosphatase, has an ortholog in C. hominis (Chro.10434), but is absent in Cryptosporidium chipmunk genotype I and $C$. meleagridis (Additional file 1: Table S1). The ortholog of another dUTP diphosphatase gene in $C$. parvum (cgd7_5170), however, is present in Cryptosporidium chipmunk genotype I (Cch_42.3131).

\section{$\mathrm{N}$-glycan and GPI-anchor precursors in Cryptosporidium chipmunk genotype I}

A secondary loss of Alg genes in asparagine (N)-linked glycosylation was reported in apicomplexans [24]. The biosynthesis of $\mathrm{N}$-glycans is different not only among apicomplexan parasites but also within the genus Cryptosporidium. Similar to C. hominis, C. parvum, C. meleagridis, and C. ubiquitum, Cryptosporidium chipmunk genotype I possesses nine sugars in N-glycan precursors, compared to eight sugars in C. baileyi and five in C. andersoni.

In glycosylphosphatidylinositol (GPI) anchor biosynthesis, the essential phosphatidylinositol glycan (PIG)-B was detected in Cryptosporidium chipmunk genotype I but lost in C. ubiquitum. Similar to other Cryptosporidium spp., genes encoding PIG-W and glycosylphosphatidylinositol deacylase (PGAP1) involved in the acylation 
Table 2 Comparison of essential metabolic pathways among Cryptosporidium spp. and some other common apicomplexan parasites

\begin{tabular}{|c|c|c|c|c|c|c|c|c|c|c|}
\hline Category & Metabolic pathway & Cchi & Cpar & Chom & Cmel & Cubi & Cbai & Cand & Pfal & Tgon \\
\hline \multirow{27}{*}{$\begin{array}{l}\text { Carbohydrate and } \\
\text { energy metabolism }\end{array}$} & Glycolysis & + & + & + & + & + & + & + & + & + \\
\hline & Methylcitrate cycle & - & - & - & - & - & - & - & - & + \\
\hline & TCA cycle & - & - & - & - & - & - & + & + & + \\
\hline & Pentose phosphate pathway & - & - & - & - & - & - & - & + & + \\
\hline & Shikimate biosynthesis & - & - & - & - & - & - & - & + & + \\
\hline & Folate biosynthesis & - & - & - & - & - & - & - & + & + \\
\hline & Synthesis of pterin & - & - & - & - & - & - & - & - & + \\
\hline & Galactose metabolism & - & - & - & - & - & - & - & - & + \\
\hline & Synthesis of starch & + & + & + & + & + & + & + & - & + \\
\hline & Synthesis of trehalose & + & + & + & + & + & + & + & - & + \\
\hline & Synthesis of 1,3-beta-glucan & - & - & - & - & - & - & - & - & + \\
\hline & Conversion between UDP-Glc and UDP-Gal & + & + & + & + & + & + & + & - & + \\
\hline & Conversion between GDP-Man and GDP-Fuc & - & - & - & - & - & - & - & + & + \\
\hline & Conversion from UDP-Glc to UDP-GlcA to UDP-Xyl & + & + & + & + & + & + & + & - & - \\
\hline & Synthesis of mannitol from fructose & + & + & + & + & + & + & + & - & - \\
\hline & Fatty acid biosynthesis in cytosol (FAS I) & + & + & + & + & + & + & + & - & + \\
\hline & Fatty acid biosynthesis in apicoplast (FAS II) & - & - & - & - & - & - & - & + & + \\
\hline & Fatty acid degradation & - & - & - & - & - & - & - & - & + \\
\hline & Oxidative phosphorylation (NADH dehydrogenase) & + & + & + & + & + & + & + & + & + \\
\hline & Oxidative phosphorylation (Complex II) & - & - & - & - & - & - & + & + & + \\
\hline & Oxidative phosphorylation (Complex III) & - & - & - & - & - & - & 1 sub & + & + \\
\hline & Oxidative phosphorylation (Complex IV) & - & - & - & - & - & - & - & + & + \\
\hline & F-ATPase & 2 sub & $2 \mathrm{sub}$ & 2 sub & 2 sub & $2 \mathrm{sub}$ & $2 \mathrm{sub}$ & + & + & + \\
\hline & Alternative oxidase (AOX) & + & + & + & + & - & - & + & - & - \\
\hline & Glyoxalase metabolism producing D-lactate & - & - & - & - & - & - & - & + & + \\
\hline & Synthesis of isoprene (MEP/DOXP) & - & - & - & - & - & - & - & + & + \\
\hline & Synthesis of farnesyl/polyprenyl diphosphate & + & + & + & + & - & - & + & + & + \\
\hline \multirow[t]{4}{*}{ Nucleotide metabolism } & Synthesis of purine rings de novo & - & - & - & - & - & - & - & - & - \\
\hline & Conversion from IMP to XMP & + & + & + & + & + & - & - & + & + \\
\hline & Conversion from XMP to GMP & - & + & + & - & - & - & - & + & + \\
\hline & Synthesis of pyrimidine de novo & - & - & - & - & - & - & - & + & + \\
\hline \multirow{12}{*}{$\begin{array}{l}\text { Amino acid } \\
\text { metabolism }\end{array}$} & Synthesis of alanine from pyruvate & - & - & - & - & - & - & - & - & + \\
\hline & Synthesis of glutamate from nitrite/nitrate & - & - & - & - & - & - & - & + & + \\
\hline & Conversion from glutamate to glutamine & + & + & + & + & + & + & + & + & + \\
\hline & Synthesis of aspartate from oxaloacetate and glutamate & - & - & - & - & - & - & - & + & + \\
\hline & Conversion from aspartate to asparagine & + & + & + & + & + & - & - & + & + \\
\hline & Conversion from glutamate to proline & + & + & + & + & + & + & + & - & + \\
\hline & Synthesis of serine from glycerate/glycerol phosphate & - & - & - & - & - & - & - & - & + \\
\hline & Conversion from serine to cysteine & - & - & - & - & - & - & - & - & + \\
\hline & Conversion from serine to glycine & + & + & + & + & + & + & + & + & + \\
\hline & Recycle homocysteine into methionine & - & - & - & - & - & - & - & + & + \\
\hline & Synthesis of lysine from aspartate & - & - & - & - & - & - & - & - & + \\
\hline & Synthesis of threonine from aspartate & - & - & - & - & - & - & - & - & + \\
\hline
\end{tabular}


Table 2 Comparison of essential metabolic pathways among Cryptosporidium spp. and some other common apicomplexan parasites (Continued)

\begin{tabular}{|c|c|c|c|c|c|c|c|c|c|c|}
\hline Category & Metabolic pathway & Cchi & Cpar & Chom & Cmel & Cubi & Cbai & Cand & Pfal & Tgon \\
\hline & Synthesis of ornithine from arginine & - & - & - & - & - & - & - & + & - \\
\hline & Synthesis of ornithine from proline & - & - & - & - & - & - & - & + & + \\
\hline & Synthesis of polyamine from ornithine & - & - & - & - & - & - & - & + & - \\
\hline & Polyamine pathway backward & + & + & + & + & + & + & + & - & + \\
\hline & Degradation of branch-chain amino acids & - & - & - & - & - & - & - & - & + \\
\hline & Synthesis of tryptophan & + & + & + & - & + & - & - & - & - \\
\hline & Aromatic amino acid hydroxylases (AAAH) & - & - & - & - & - & - & - & - & + \\
\hline \multirow[t]{13}{*}{ Vitamin and others } & Synthesis of ubiquinone (Coenzyme Q) & + & + & + & + & - & - & + & + & + \\
\hline & Synthesis of Fe-S cluster & + & + & + & + & + & + & + & + & + \\
\hline & Synthesis of heme & - & - & - & - & - & - & - & + & + \\
\hline & Synthesis of thiamine (Vitamin B1) & - & - & - & - & - & - & - & + & - \\
\hline & Conversion from thiamine to thiamine pyrophosphate (TPP) & - & - & - & - & - & - & - & + & + \\
\hline & Synthesis of FMN/FAD from riboflavin & - & - & - & - & - & - & - & + & + \\
\hline & Synthesis of pyridoxal phosphate (Vitamin B6) de novo & - & - & - & - & - & - & - & + & + \\
\hline & Synthesis of $N A D(P)+$ de novo from nicotinate/nicotinamide & - & - & - & - & - & - & - & + & + \\
\hline & Synthesis of pantothenate from valine & - & - & - & - & - & - & - & - & + \\
\hline & Synthesis of CoA from pantothenate & + & + & + & + & + & + & + & + & + \\
\hline & Synthesis of lipoic acid de novo in apicoplast & - & - & - & - & - & - & - & + & + \\
\hline & Salvage of lipoic acid in mitochondria & - & - & - & - & - & - & + & + & + \\
\hline & Synthesis of porphyrin/cytochrome proteins & - & - & - & - & - & - & - & + & + \\
\hline
\end{tabular}

Plus symbols denote that these metabolic pathways were identified in this apicomplexan parasite, whereas minus symbols denote that these metabolic pathways are absent from this apicomplexan parasite. Abbreviation: Cchi Cryptosporidium chipmunk genotype I, Cpar Cryptosporidium parvum, Chom C. hominis, Cmel C. meleagridis, Cubi C. ubiquitum, Cbai C. baileyi, Cand C. andersoni, Pfal Plasmodium falciparum, Tgon Toxoplasma gondii

and de-acylation of inositol are absent in Cryptosporidium chipmunk genotype I.

\section{Characteristics of invasion-related proteins in Cryptosporidium chipmunk genotype I}

Cryptosporidium chipmunk genotype I and other intestinal Cryptosporidium spp. possess similar numbers and components of major protein families, including some of those involved in invasion, such as protein kinases and TRAPs. Cryptosporidium species, however, differ in the number of genes encoding other invasion-related proteins, such as insulinase-like peptidases, MEDLE secretory proteins, and mucin glycoproteins. For example, gastric species $C$. andersoni and $C$. muris have fewer genes encoding insulinase-like peptidases (Fig. 5). Compared with $C$. parvum, two of the 23 insulinase-like protease genes and four of the six MEDLE family protein genes are lost in Cryptosporidium chipmunk genotype I, all located at the subtelomeric regions of chromosomes 5 and 6 (Additional file 1: Table S2). A new gene (Cch_105.391) of the insulinase gene family, which has significant sequence similarity to cgd3_4260, was detected at the $5^{\prime}$ end of chromosome 7 (contig_105). Furthermore, all three major human-infecting species, C. parvum, C. hominis, and C. meleagridis, possess MEDLE protein genes, but none of them were observed in C. ubiquitum, C. baileyi, C. andersoni, or $C$. muris (Additional file 1: Table S2).

Comparisons of mucin-type glycoproteins among eight Cryptosporidium species had shown a high divergence between human-infecting and animal-infecting species. The gp60/40/15 complex, which is a single-copy gene in Cryptosporidium chipmunk genotype $\mathrm{I}$, is absent in $C$. andersoni and $C$. muris, but has 7 paralogous genes in two clusters in C. baileyi. Cryptosporidium chipmunk genotype I possesses a series of mucin-type glycoproteins, such as CP2, but many of them are absent in C. baileyi, $C$. andersoni, or C. muris (Additional file 1: Table S2). Phylogenetic analysis of invasion-related proteins, including mucin-type glycoproteins, insulinase-like proteases and TRAPs, confirmed the close relatedness of Cryptosporidium chipmunk genotype I to human-infecting species (Fig. 2b-d).

\section{Other genes gains and losses in Cryptosporidium chipmunk genotype I}

Compared with other related Cryptosporidium spp., gains and losses of several other genes were detected in 
Table 3 Putative transporters in Cryptosporidium spp. and some other common apicomplexan parasites ${ }^{a}$

\begin{tabular}{|c|c|c|c|c|c|c|c|c|c|c|c|}
\hline Substrates & Cellular location & Cchi & Cpar & ChomUde & Cmel & Cubi & Cbai & Cand & Cmur & Pfal & Tgon \\
\hline Hexose & & 2 & 2 & 2 & 2 & 2 & 2 & 2 & 3 & 2 & 5 \\
\hline Triose phosphate & Plasma/Apicoplast membrane & 7 & 8 & 8 & 8 & 8 & 7 & 8 & 8 & 4 & 4 \\
\hline Amino acids & Plasma membrane & 10 & 10 & 10 & 10 & 10 & 10 & 12 & 12 & 1 & 6 \\
\hline Nucleobase/nucleoside & Plasma membrane & 1 & 1 & 1 & 1 & 1 & 1 & 1 & 1 & 4 & 4 \\
\hline Nucleotide-sugar & Plasma membrane & 3 & 3 & 3 & 3 & 3 & 2 & 2 & 2 & 1 & 4 \\
\hline Folate/pterine & Plasma membrane & 1 & 1 & 2 & 1 & 1 & 1 & 1 & 1 & 2 & 7 \\
\hline Formate/nitrite & & 0 & 0 & 0 & 0 & 0 & 0 & 0 & 0 & 1 & 3 \\
\hline GABA (aminobutanoate) & Plasma/Mitochondrial membrane & 0 & 0 & 0 & 0 & 0 & 0 & 0 & 0 & 2 & 5 \\
\hline Acetyl-CoA & & 1 & 1 & 1 & 1 & 1 & 1 & 1 & 1 & 1 & 1 \\
\hline Chloride & & 0 & 0 & 0 & 0 & 0 & 0 & 0 & 0 & 0 & 2 \\
\hline Inorganic phosphate & & 0 & 0 & 0 & 0 & 0 & 0 & 0 & 0 & 1 & 1 \\
\hline Sulfate & & 1 & 1 & 1 & 1 & 1 & 1 & 1 & 1 & 1 & 4 \\
\hline Sodium/potassium/calcium & & 2 & 2 & 2 & 2 & 2 & 2 & 3 & 3 & 0 & 9 \\
\hline Zinc & & 2 & 2 & 2 & 2 & 2 & 2 & 2 & 2 & 2 & 4 \\
\hline Copper & & 1 & 1 & 1 & 1 & 1 & 1 & 1 & 1 & 2 & 3 \\
\hline Choline & Plasma membrane & 0 & 0 & 0 & 0 & 0 & 0 & 0 & 0 & 1 & 2 \\
\hline Cadmium/zinc/cobalt (efflux) & Plasma membrane & 1 & 1 & 1 & 1 & 1 & 1 & 1 & 1 & 1 & 1 \\
\hline Glycerol/water & Plasma membrane & 0 & 0 & 0 & 0 & 0 & 0 & 0 & 0 & 2 & 2 \\
\hline $\mathrm{ABC}$ transporter & Plasma membrane & 21 & 21 & 21 & 21 & 21 & 22 & 21 & 21 & 16 & 24 \\
\hline Mitochondrial carrier & Mitochondrial membrane & 8 & 9 & 9 & 8 & 6 & 6 & 13 & 12 & 14 & 21 \\
\hline
\end{tabular}

Cchi Cryptosporidium chipmunk genotype I, Cpar Cryptosporidium parvum, ChomUde C. hominis UdeA01, Cmel C. meleagridis, Cubi C. ubiquitum, Cbai C. baileyi, Cand C. andersoni, Cmur C. muris, Pfal Plasmodium falciparum, Tgon Toxoplasma gondii

${ }^{a}$ The detection of these transporter proteins was based on the Pfam search results

Cryptosporidium chipmunk genotype I. One 4500-bp insertion, which contains a Cryptosporidium chipmunk genotype I-specific gene (Cch_13.573) was seen at the 3' end of chromosome 4. In the large insertion at the $3^{\prime}$ end of chromosome 5 (contig_35) in Cryptosporidium chipmunk genotype I, Cch_35.2955 is a paralog of Cch_40.3117, Cch_7.3568 and Cch_1.1. Six members (Chro.00007, Chro.60010, Chro.60630, Chro.80010, Chro.60631, and Chro.60634) of this gene family were detected in C. hominis but only three (cgd5/6_5500, cgd6_5500, and cgd8_10) were detected in C. parvum. In contrast, the ortholog of $c g d 4 \_3690$, which encodes a low complexity protein with a large glycine-rich repeat, was lost in Cryptosporidium chipmunk genotype I. The same is also true for the gene for a cysteine-rich protein with a signal peptide in C. parvum (cgd4_4500), C. hominis (Chro.40511), and C. meleagridis (C_mele_24106.404). Similar to C. hominis and C. meleagridis, Cryptosporidium chipmunk genotype I has only one copy of the paralogous genes cgd8_660_670 and cgd8_680_690. Similarly, orthologs of cgd4_10, cgd7_5530, cgd8_4180 and cgd8_5420 were not detected in Cryptosporidium chipmunk genotype I (Additional file 1: Table S1). They are mostly subtelomeric genes encoding hypothetical proteins. Among 23 genes lost in Cryptosporidium chipmunk genotype I, 11 encode proteins with signal peptides (cgd4_10, cgd4_4500, cgd7/5_4510, cgd7/5_4530, cgd7/5_4590, cgd5/6_5480, cgd5/6_5490, cgd5/6_5520-5510, cgd6_5520-5510, cgd7_ 1280, cgd8_660_70) and 19 are located in the subtelomeric regions (cgd1_3860, cgd3_370, cgd4_10, cgd4_3690, cgd4_4500, cgd5/6_5490, cgd5/6_5520-5510, cgd6_5500, cgd6_5520-5510, cgd7/5_4580,cgd7/5_4590,cgd7/5_4610, cgd7/5_4510, cgd7/5_4520, cgd7/5_4530, cgd7_5530, cgd8_10,cgd8_660_70,cgd8_5420).

\section{Highly divergent genes between Cryptosporidium chipmunk genotype I and Cryptosporidium parvum}

The putative proteome of Cryptosporidium chipmunk genotype I was compared with the annotated protein-encoding genes of $C$. parvum and C. ubiquitum. We found 49 highly divergent genes between Cryptosporidium chipmunk genotype I and these two Cryptosporidium species with an amino acid identity below 65\% (Additional file 1: Table S3). Among them, 43 (87.8\%) genes encode proteins with signal peptides, 41 (84.9\%) are located in the subtelomeric regions, and 25 (51.0\%) possess paralogous genes. Many of the genes encode 


\begin{tabular}{|c|c|c|c|c|c|c|c|c|c|c|}
\hline Protein family & Pfam ID & Cchi & Cpar & ChomT & ChomU & Cmel & Cubi & Cbai & Cand & Cmur \\
\hline Protein kinase & PF00069 & 75 & 79 & 75 & 78 & 78 & 80 & 78 & 81 & 74 \\
\hline Insulinase & PF00675; PF05193 & 20 & 22 & 18 & 19 & 19 & 19 & 18 & 12 & 14 \\
\hline Thrombospondin-related adhesive protein & PF00090 & 12 & 12 & 12 & 12 & 12 & 11 & 11 & 12 & 12 \\
\hline Protein phosphatase 2C family protein & PF00481 & 10 & 11 & 10 & 11 & 11 & 11 & 10 & 10 & 11 \\
\hline AP2 transcription factor & PF00847 & 10 & 11 & 9 & 11 & 10 & 11 & 12 & 11 & 10 \\
\hline Cysteine protease & PF00112 & 5 & 5 & 4 & 6 & 6 & 5 & 6 & 5 & 5 \\
\hline Kazal-type serine protease inhibitor & PF00050; PF07648 & 4 & 4 & 4 & 3 & 4 & 4 & 4 & 4 & 4 \\
\hline PAN domain-containing protein & PF00024; PF08277; & 1 & 3 & 3 & 2 & 1 & 2 & 0 & 3 & 1 \\
\hline Rhomboid protease & PF01694 & 3 & 3 & 2 & 3 & 3 & 3 & 3 & 4 & 4 \\
\hline Subtilisin-like serine protease & PF00082 & 2 & 2 & 0 & 3 & 3 & 2 & 3 & 2 & 2 \\
\hline Selectins with sushi domain & PF00084 & 2 & 2 & 2 & 2 & 2 & 2 & 2 & 2 & 2 \\
\hline Cysteine-rich secretory protein & PF00188 & 2 & 2 & 2 & 2 & 2 & 2 & 2 & 2 & 2 \\
\hline
\end{tabular}

Fig. 5 Comparison of major invasion-related protein families among Cryptosporidium species. The number of each protein family was identified based on Pfam domain search. The dark yellow cell represents the largest number of members in the protein families while the green cell represents the smallest number of members in the protein families in Cryptosporidium spp. Because of highly-fragmented draft genome of $C$. hominis TU502, some Pfam domains were not detected in C. hominis but observed in C. hominis UKH1. Abbreviations of taxa: Cryptosporidium chipmunk genotype I (Cchi); Cryptosporidium parvum (Cpar); C. hominis TU502 (ChomT); C. hominis UKH1 (ChomU); C. meleagridis (Cmel); C. ubiquitum (Cubi); C. baileyi (Cbai); C. andersoni (Cand); C. muris (Cmur)

mucins, Cryptosporidium-specific SKSR or FLGN families, and low complexity proteins.

\section{Genes under selection pressure}

The $\mathrm{dN} / \mathrm{dS}$ analysis was used to identify orthologous genes under selection between Cryptosporidium chipmunk genotype I and C. parvum, two species with different host ranges. Genes encoding invasion-related proteins, secreted proteins, and surface-associated proteins, which could be involved in host immune responses, exhibited elevated $\mathrm{dN} / \mathrm{dS}$ ratios. In contrast, genes encoding proteins that are involved in metabolic pathways had reduced dN/dS ratios (Fig. 6). Among all orthologous genes, there are only six genes with $\mathrm{dN} / \mathrm{dS}$ ratios $>1$, thus under positive selection. Two of them (C_ch_8.3686 and C_ch_8.3664) encode ABC transporters. Among the 20 orthologous genes with the highest $\mathrm{dN} / \mathrm{dS}$ ratios, 9 (45\%) encode proteins with signal peptides, 11 (55\%) encode membrane-bound proteins, and $14(70 \%)$ are located in the subtelomeric regions (Table 4).

\section{Discussion}

Results of comparative genomic analysis in this study suggest that the metabolic pathways in Cryptosporidium chipmunk genotype I are similar to those in major human-infecting Cryptosporidium species, including $C$. parvum, C. hominis, and C. meleagridis $[18,19]$. Unlike
C. muris and C. andersoni [12], Cryptosporidium chipmunk genotype I does not use the TCA cycle or conventional oxidative phosphorylation for energy production. Like C. parvum and C. hominis, Cryptosporidium chipmunk genotype I possesses an alternative oxidative phosphorylation chain, which is lost in C. ubiquitum and $C$. baileyi. The similarity in metabolism between Cryptosporidium chipmunk genotype I and other human-infecting species is a reflection of their genetic relatedness. This has been confirmed by results of phylogenetic analyses of 100 conserved proteins and several families of invasion-related proteins.

The genome organization of Cryptosporidium chipmunk genotype I is also similar to other intestinal Cryptosporidium species. The genome sizes of the human-pathogenic Cryptosporidium species are all near $9 \mathrm{Mb}$, which is slightly smaller than the $9.21 \mathrm{Mb}$ in $C$. muris. As expected, Cryptosporidium chipmunk genotype I has a gene content just slightly lower than human-pathogenic Cryptosporidium species. In contrast, the genomes of seven Eimeria species in chickens vary significantly in size $(46.2-69.5 \mathrm{Mb})$, with the number of predicted protein-encoding genes over a range of 6000-10,000 genes [25]. Similar differences in genome sizes and gene contents exist among Plasmodium spp. [26] or Babesia spp. [27]. Thus, compared with other apicomplexans, intestinal Cryptosporidium species have shown high genome conservation. The differences in 


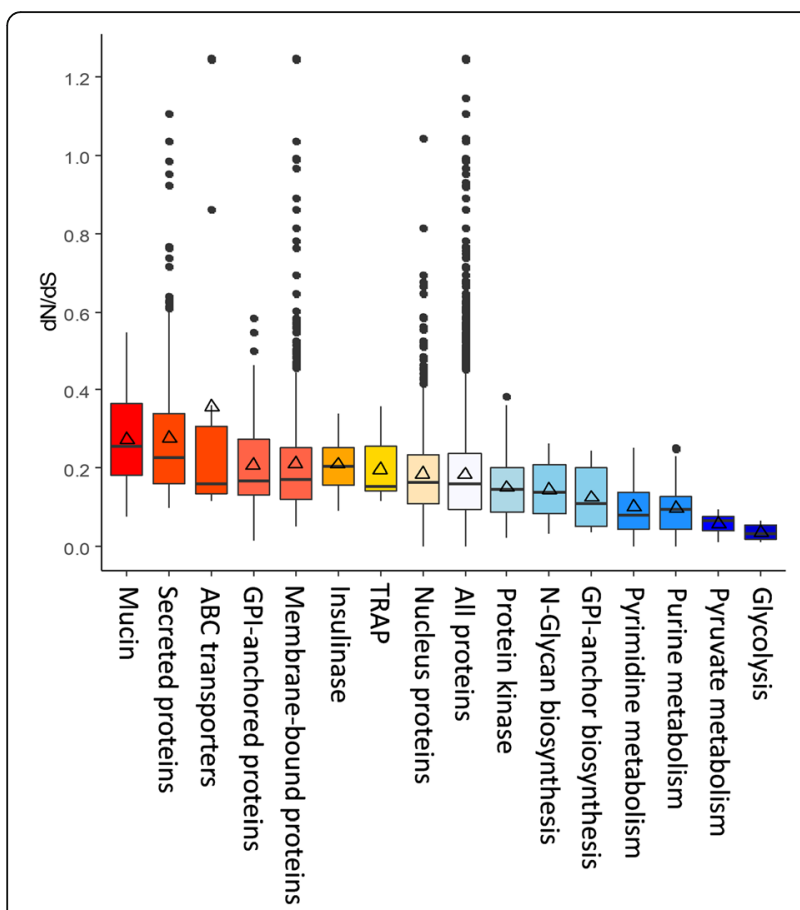

Fig. 6 Selective pressure in genes encoding major groups of proteins as indicated by the $\mathrm{dN} / \mathrm{dS}$ ratios between Cryptosporidium chipmunk genotype I and C. parvum. Red categories represent groups of proteins with mean $\mathrm{dN} / \mathrm{dS}$ ratios higher than all proteins in the proteome, while blue categories represent groups of proteins with reduced $\mathrm{dN} /$ dS ratios. Triangles: mean dN/dS; horizontal black line: median dN/dS

host range among intestinal Cryptosporidium species could be potentially caused by the minor gene gains and losses or sequence polymorphism in SPDs encoded by genes located in subtelomeric regions.

Compared with C. parvum, a major reduction in gene content in Cryptosporidium chipmunk genotype I is in the number of subtelomeric genes encoding secreted MEDLE proteins and insulinase-like proteases. Cryptosporidium parvum has two subtelomeric genes for insulinase-like proteases (cgd6_5520-5510 and a paralog of it), compared to one in Cryptosporidium chipmunk genotype I (Cch_105.391, a paralog of cgd3_4260), one (cgd5/6_5520-5510 ortholog) in C. meleagridis, and none in $C$. hominis. The loss of these and some subtelomeric genes encoding secreted MEDLE family proteins in Cryptosporidium chipmunk genotype I (6, 2, 2, and 1 copy for C. parvum, C. meleagridis, Cryptosporidium chipmunk genotype $\mathrm{I}$, and $C$. hominis, respectively) may contribute to its narrow host range. In contrast, the number of genes for mucin-type glycoproteins in Cryptosporidium chipmunk genotype I is similar to that in human-infecting species. Cryptosporidium chipmunk genotype I, C. hominis, C. parvum, and C. meleagridis possess 24 genes encoding mucin-type glycoproteins, whereas gastric species, such as $C$. andersoni and $C$. muris, have lost 16 of them, including those encoding gp60, Muc4, and Muc5, which are important in the attachment and invasion of C. parvum [28].

The significance of other gene gains and losses in the genome of Cryptosporidium chipmunk genotype I is not yet clear. The gene Cch_35.2955, which has three other paralogs in Cryptosporidium chipmunk genotype I, was annotated as a new gene at the $3^{\prime}$ end of chromosome 5 . C. parvum has three orthologs (cgd5/6_5500, cgd6_5500 and cgd8_10) while C. hominis has six (Chro.00007, Chro.60010, Chro.60630, Chro.60631, Chro.60634 and Chro.80010). There is also a loss of the cgd8_660_670 ortholog in chromosome 8 of Cryptosporidium chipmunk genotype I. This gene encodes a large low complexity protein in $C$. parvum and has a paralog (cgd8_680_690) downstream. Likewise, C. hominis has only one member of this multigene family [11]. In addition, Cryptosporidium chipmunk genotype I has lost several other genes, such as orthologs of cgd4_3690 (encoding a large glycine-rich repeat low complexity protein), cgd4_4500 (encoding a cysteine-rich protein), cgd5_2960 (encoding a DEAD/DEAH box helicase), cgd5_2980 (encoding another DEAD/DEAH box helicase), and cgd8_4180 (encoding a glycine-rich low complexity protein) in C. parvum. Although the functions of these proteins are mostly unknown, these gene losses could contribute to the narrow host range of Cryptosporidium chipmunk genotype I.

Most of the highly divergent genes between Cryptosporidium chipmunk genotype I and other Cryptosporidium spp. encode secreted proteins and half of the highly divergent genes are located in the subtelomeric regions. These secreted proteins could potentially be SPDs in Cryptosporidium spp., thus play a role in host specificity of Cryptosporidium spp., especially SKSR, FLGN and mucin proteins. Among them, the number of genes encoding SKSR proteins is different between C. parvum IIa and IId subtype families, which have different host preference [13]. As in C. parvum IId subtype family, 7 paralogous genes encoding SKSR proteins were detected in Cryptosporidium chipmunk genotype I, but the sequence of these genes were divergent from those in C. parvum. The high sequence diversity of mucin-type glycoproteins between human- and animal-infecting species may also contribute to the host specificity and tissue tropism among Cryptosporidium spp. Previously, secretory proteins from dense granules (GRAs), micronemes (MICs), rhoptries (ROPs), and the SRS super-family were identified as potential SPDs in T. gondii, which could be responsible for differences in transmission modes, pathogenicity, and host range among T. gondii strains [29].

The elevated $\mathrm{dN} / \mathrm{dS}$ ratios for secreted and surfaceassociated proteins support their function as SPDs. These proteins are apparently under selection, perhaps 
Table 4 Twenty orthologous genes with the highest dN/dS ratios between Cryptosporidium chipmunk genotype I and Cryptosporidium parvum

\begin{tabular}{|c|c|c|c|c|c|c|}
\hline $\begin{array}{l}\text { Gene in Cryptosporidium } \\
\text { chipmunk genotype I }\end{array}$ & Gene in C. parvum & $\begin{array}{l}\mathrm{dN} / \mathrm{dS} \\
\text { ratio }\end{array}$ & TMHMM & $\begin{array}{l}\text { Signal } \\
\text { peptide }\end{array}$ & $\begin{array}{l}\text { Subtelomeric } \\
\text { location }\end{array}$ & Annotation \\
\hline C_ch_8.3686 & cgd2_90 & 1.25 & YES & NO & YES & $\begin{array}{l}\text { ABC transporter with } 9 \text { transmembrane } \\
\text { domains and } 2 \text { AAA domains }\end{array}$ \\
\hline C_ch_8.3664 & cgd2_70 & 1.24 & YES & NO & YES & $\begin{array}{l}\text { ABC transporter, with } 12 \text { transmembrane } \\
\text { domains and } 2 \text { AAA domains }\end{array}$ \\
\hline C_ch_11.460 & cgd3_60 & 1.15 & NO & NO & YES & Putative hydrolase \\
\hline C_ch_105.389 & cgd5_4570 & 1.11 & NO & NO & YES & $\begin{array}{l}\text { Hypothetical protein with disordered } \\
\text { regions }\end{array}$ \\
\hline C_ch_10.167 & cgd7_640 & 1.04 & NO & NO & YES & $\begin{array}{l}\text { Prp16p pre-mRNA splicing factor, HrpA } \\
\text { family SFIl helicase }\end{array}$ \\
\hline C_ch_22.2069 & cgd6_3780 & 1.04 & YES & YES & NO & $\begin{array}{l}\text { Hypothetical membrane protein with } \\
\text { signal peptide and transmembrane } \\
\text { domain }\end{array}$ \\
\hline C_ch_10.307 & cgd8_5370 & 0.99 & YES & NO & YES & Conserved secreted protein \\
\hline C_ch_37.2969 & cgd7_5510 & 0.99 & YES & NO & YES & Secreted protein \\
\hline C_ch_105.390 & cgd6_5490 & 0.98 & NO & YES & YES & $\begin{array}{l}\text { Conserved hypothetical protein with low } \\
\text { sequence complexity regions }\end{array}$ \\
\hline C_ch_1.56 & cgd6_50 & 0.97 & YES & NO & YES & Predicted secreted protein \\
\hline C_ch_50.3279 & cgd1_120 & 0.95 & NO & YES & YES & $\begin{array}{l}\text { Predicted secreted protein with a } \\
\text { cysteine cluster at the C-terminus }\end{array}$ \\
\hline C_ch_18.1418 & cgd4_2900 & 0.93 & NO & NO & NO & Polyketide synthase \\
\hline C_ch_19.1673 & cgd4_2510 & 0.92 & NO & YES & NO & Predicted secreted protein \\
\hline C_ch_19.1715 & cgd3_2180 & 0.92 & NO & NO & NO & Type I fatty acid synthase \\
\hline C_ch_35.2958 & cgd5_4610 & 0.89 & YES & YES & YES & Conserved secreted protein \\
\hline C_ch_23.2117 & cgd4_1380 & 0.86 & YES & NO & NO & $\begin{array}{l}\text { ABC transporter with } 2 \text { AAA domains } \\
\text { and } 14 \text { transmembrane regions }\end{array}$ \\
\hline C_ch_50.3280 & cgd1_130 & 0.82 & YES & YES & YES & $\begin{array}{l}\text { Predicted secreted protein with a } \\
\text { cysteine cluster at the C-terminus }\end{array}$ \\
\hline C_ch_17.1234 & cgd7_3440 & 0.78 & YES & YES & NO & Predicted secreted protein \\
\hline C_ch_50.3278 & cgd1_110 & 0.77 & NO & YES & YES & Predicted secreted protein \\
\hline C_ch_21.2011 & cgd8_40 & 0.76 & YES & YES & YES & $\begin{array}{l}\text { Predicted secreted protein of } \\
\text { Cryptosporidium-specific SKSR gene } \\
\text { family }\end{array}$ \\
\hline Subtotal & - & - & $11 / 20(55.0 \%)$ & 9/20 (45.0\%) & $14 / 20(70.0 \%)$ & - \\
\hline
\end{tabular}

as a result of high immune pressure due to their importance in invasion and host-parasite interactions. A similar observation was made in comparative analysis of C. parvum and C. hominis genomes [30, 31]. Most of the genes with higher $\mathrm{dN} / \mathrm{dS}$ ratios are located in the subtelomeric regions, supporting the previous conclusion that they undergo more rapid evolution. Three genes encoding $\mathrm{ABC}$ transporters are among the top 20 genes with the highest $\mathrm{dN} / \mathrm{dS}$ ratios between Cryptosporidium chipmunk genotype I and C. parvum. ABC transporters are "key components of the cellular machinery for endobiotic and xenobiotic detoxification", thus may contribute to intrinsic drug resistance in Cryptosporidium spp. [32]. These genes are expected to be under positive selective pressure. Indeed several $A B C$ transporters were previously identified as highly divergent genes between C. parvum IIa (zoonotic) and IIc (anthroponotic) subtype families [33]. Interestingly, two of them, cgd2_80 and cgd2_90, are also within the same region ( $c g d 2 \_70$ and $\left.c g d 2 \_90\right)$ identified as going through positive selection in the present study. These three $A B C$ transporters encoded by genes within the ABC transporter gene cluster (cgd2_60 to cgd2_90) could be potential targets for drug development.

\section{Conclusions}

Cryptosporidium chipmunk genotype I apparently possesses metabolic pathways and invasion-related proteins similar to those in C. parvum, C. hominis, and C. meleagridis. This supports the human-pathogenic nature of Cryptosporidium chipmunk genotype I. The loss of two 
subtelomeric genes of insulinase-like proteases and four genes of secreted MEDLE family proteins compared with C. parvum are in agreement with the narrowed host range of Cryptosporidium chipmunk genotype I. Sequence differences and selection in genes encoding secreted and surface-associated proteins and $A B C$ transporters could contribute to other biological differences among intestinal Cryptosporidium species. More studies on functional genomics and the basic biology of multiple isolates of Cryptosporidium chipmunk genotype I are needed to confirm some of the conclusions and improve our understanding of the emerging human pathogen.

\section{Methods}

\section{Specimen collection and whole-genome sequencing}

Cryptosporidium chipmunk genotype I isolate 37,763 was collected from one human specimen in Vermont and diagnosed by DNA sequence analysis of the small subunit rRNA gene [34]. Oocysts were purified from the specimen using sucrose and cesium chloride density gradient centrifugations and immunomagnetic separation [35]. The purified oocysts were subjected to five freeze-thaw cycles and overnight digestion with proteinase K. Genomic DNA was extracted from the oocysts by using the QIAamp ${ }^{\circ}$ DNA Mini Kit (Qiagen Sciences, Maryland, 20,874, USA) and amplified by REPLI-g Midi Kit (Qiagen $\mathrm{GmbH}$, Hilden, Germany). For whole-genome sequencing, 250-bp paired-end reads were generated from the DNA by using Illumina HiSeq 2500 analysis of an Illumina TruSeq (v3) library. After trimming for adapter sequences and poor sequence quality $(<$ phred score less than 25$)$, the sequence reads were assembled de novo by using CLC Genomics Workbench with word size of 63 and bulb size of 500 . In a secondary analysis, the genome was also assembled using SPAdes 3.1 (http://cab.spbu.ru/software/spades/).

\section{Genome structure analysis and gene prediction}

An alignment of Cryptosporidium chipmunk genotype I genome and published genomes of $C$. parvum IOWA isolate [18], C. hominis, C. ubiquitum [12], C. baileyi [20] and C. andersoni [12] was constructed by using Mauve 2.3.1 [36] with default parameters. Circos 0.69 [37] was used to visualize the syntenic relationship (regions with orthologous genes) between the Cryptosporidium chipmunk genotype I genome and other four genomes.

AUGUSTUS 3.2.1 [38], Geneid 1.4 [39], and GeneMark-ES [40] were used to predict proteinencoding genes in Cryptosporidium chipmunk genotype I with the default settings, after training AUGUSTUS and Geneid with the gene model of the C. parvum IOWA genome. Consensus predictor EVidence Modeler [41] was used to generate the gene set based on predictions from the three software packages.

\section{Functional annotation}

The predicted genes of Cryptosporidium chipmunk genotype I were annotated by using BLASTP [42] search of the GenBank NR database. Signal peptides and the transmembrane domains were predicted by using SignalP 4.1 [43] and TMHMM 2.0 [44], respectively. GPI-SOM webserver [45] was used to identify proteins with GPI anchor sites. Metabolism analysis was performed using the web server KAAS [46] with the BBH (Bi-directional Best Hit) method and eukaryote gene model. The online databases KEGG (Kyoto Encyclopedia of Genes and Genomes)(http://www.genome.jp/kegg/), Pfam (http://pfam.xfam.org/) [47], and LAMP (Library of Apicomplexan Metabolic Pathways, release-2) [48] were used to annotate catalytic enzymes, functional proteins, and metabolic pathways within the genome.

\section{Comparative genomics analysis}

BLASTP was used for sequence similarity searches among Cryptosporidium chipmunk genotype I and other Cryptosporidium genomes in CryptoDB (http://cryptodb. org/cryptodb/). Homologous gene families were identified by using OrthoMCL [49]. BLASTP and OrthoMCL were run with e-value thresholds of $1 \mathrm{e}-3$ and 1e-5, respectively. A Venn diagram of shared orthologs and species-specific genes of C. parvum, C. hominis, C. ubiquitum, C. meleagridis, and Cryptosporidium chipmunk genotype I was drawn using VennPainter (https://github. com/linguoliang/VennPainter). The relationship among proteins in Cryptosporidium chipmunk genotype I, C. parvum, and C. meleagridis was visualized with Gephi (https://gephi.org/) with the Fruchterman-Reingold layout based on the result of BLASTP homology analysis, with threshold of protein pairs sharing $30 \%$ identity over 100 amino acids. Comparative analyses of metabolism among Cryptosporidium spp. were based on the results of KAAS and data of LAMP. Pfam search results were used in comparisons of transporter proteins and invasion-related proteins among Cryptosporidium species. The nonsynonymous to synonymous substitution (dN/dS) ratios between Cryptosporidium chipmunk genotype I and C. parvum were calculated for orthologous genes using KaKs_Calculator 2.0 [50].

\section{Phylogenetic analysis}

The amino acid sequences of 100 single-copy orthologs shared among Cryptosporidium species and Gregarina niphandrodes were extracted and concatenated to construct a phylogenetic tree. MUSCLE [51] was used to align the concatenated sequences and with poorly aligned positions being eliminated from the alignment 
by using Gblocks [52]. Phylogenetic trees based on maximum likelihood (ML) were constructed using RAxML [53] with 1000 replications for bootstrapping. The concatenated sequence from G. niphandrodes was used as the outgroup.

\section{Additional file}

Additional file 1: Table S1. Gene gains and losses in several Cryptosporidium species. Table S2. Major putative invasion- and host specificity-associated genes in Cryptosporidium spp. Table S3. Highly divergent genes among Cryptosporidium chipmunk genotype I, C. parvum and C. ubiquitum. (XLSX $23 \mathrm{~kb}$ )

\section{Abbreviations}

AAA: ATPases-associated with diverse cellular activities; ABC: ATP-binding cassette; acetyl-CoA: acetyl-coenzyme A; AOX: Alternative oxidase; ATP: Adenosine triphosphate; dUTP: deoxyuridine triphosphate; FPP: Farnesyl diphosphate; GMP: Guanosine monophosphate;

GPI: Glycosylphosphatidylinositol; GRAs: Dense granules; KEGG: Kyoto Encyclopedia of Genes and Genomes; LAMP: Library of Apicomplexan Metabolic Pathways; MICs: Micronemes; OAA: Oxaloacetate; PEP: Phosphoenolpyruvate; PGAP1: Glycosylphosphatidylinositol deacylase; PIG: Phosphatidylinositol glycan; PIG-B: Mannosyltransferase; PNO: Pyruvate: NADP+ oxidoreductase; ROPs: Rhoptries; SPDs: Secreted pathogenesis determinants; TCA: Tricarboxylic acid; TRAPs: Thrombospondin-related adhesive proteins; XMP: Xanthosine 5'-phosphate

\section{Acknowledgements}

The findings and conclusions in this report are those of the authors and do not necessarily represent the views of the Centers for Disease Control and Prevention.

\section{Funding}

This work was supported by the National Natural Science Foundation of China (31630078 and 31602042) and National Key R\&D Program of China (2017YFD0501305). The funding body did not participate in the design of the study, collection, analysis and interpretation of data, or preparation of the manuscript.

\section{Availability of data and materials}

The datasets supporting the conclusion of this article, including all Sequence Read Archive (SRA) data, genome assembly, and annotations, were submitted to NCBI BioProject under accession No. PRJNA511361.

\section{Authors' contributions}

YF and LX conceived and designed the experiments; $Y G$ and DMR collected the data; ZX and LX analyzed the data; ZX, YF and LX wrote the paper. All authors read and approved the final manuscript.

\section{Ethics approval and consent to participate}

The genome sequencing was done on delinked residual diagnostic specimens from Human Subjects Protocol No. 990115 "Use of residual human specimens for the determination of frequency of genotypes or sub-types of pathogenic parasites", which was reviewed and approved by the Institutional Reviewing Board of the Centers for Disease Control and Prevention.

\section{Consent for publication}

Not applicable.

\section{Competing interests}

The authors declare that they have no competing interests.

\section{Publisher's Note}

Springer Nature remains neutral with regard to jurisdictional claims in published maps and institutional affiliations.

\section{Author details}

State Key Laboratory of Bioreactor Engineering, School of Resources and Environmental Engineering, East China University of Science and Technology, Shanghai 200237, China. ${ }^{2}$ Key Laboratory of Zoonosis of Ministry of Agriculture, College of Veterinary Medicine, South China Agricultural University, Guangzhou 510642, China. ${ }^{3}$ Division of Foodborne, Waterborne, and Environmental Diseases, National Center for Emerging and Zoonotic Infectious Diseases, Centers for Disease Control and Prevention, Atlanta, GA 30329, USA.

Received: 9 February 2019 Accepted: 9 May 2019

Published online: 22 May 2019

\section{References}

1. Feng Y, Ryan UM, Xiao L. Genetic diversity and population structure of Cryptosporidium. Trends Parasitol. 2018;34(11):997-1011.

2. Xiao L. Molecular epidemiology of cryptosporidiosis: an update. Exp Parasitol. 2010;124(1):80-9.

3. Ryan U, Fayer R, Xiao L. Cryptosporidium species in humans and animals: current understanding and research needs. Parasitology. 2014; 141(13):1667-85.

4. Silverlas C, Mattsson JG, Insulander M, Lebbad M. Zoonotic transmission of Cryptosporidium meleagridis on an organic Swedish farm. Int J Parasitol. 2012:42(11):963-7.

5. Wang Y, Yang W, Cama V, Wang L, Cabrera L, Ortega Y, Bern C, Feng Y, Gilman R, Xiao L. Population genetics of Cryptosporidium meleagridis in humans and birds: evidence for cross-species transmission. Int J Parasitol. 2014;44(8):515-21.

6. Fayer R, Santin M, Macarisin D. Cryptosporidium ubiquitum n. sp. in animals and humans. Vet Parasitol. 2010;172(1-2):23-32.

7. Li N, Xiao L, Alderisio K, Elwin K, Cebelinski E, Chalmers R, Santin M, Fayer R, Kvac M, Ryan U, et al. Subtyping Cryptosporidium ubiquitum,a zoonotic pathogen emerging in humans. Emerg Infect Dis. 2014;20(2):217-24.

8. Insulander M, Silverlas C, Lebbad M, Karlsson L, Mattsson JG, Svenungsson B. Molecular epidemiology and clinical manifestations of human cryptosporidiosis in Sweden. Epidemiol Infect. 2013;141(5):1009-20.

9. Lebbad M, Beser J, Insulander M, Karlsson L, Mattsson JG, Svenungsson B, Axen C. Unusual cryptosporidiosis cases in Swedish patients: extended molecular characterization of Cryptosporidium viatorum and Cryptosporidium chipmunk genotype I. Parasitology. 2013;140(14):1735-40.

10. Guo Y, Cebelinski E, Matusevich C, Alderisio KA, Lebbad M, McEvoy J, Roellig DM, Yang C, Feng Y, Xiao L. Subtyping novel zoonotic pathogen Cryptosporidium chipmunk genotype I. J Clin Microbiol. 2015;53(5):1648-54.

11. Guo Y, Tang K, Rowe LA, Li N, Roellig DM, Knipe K, Frace M, Yang C, Feng Y, Xiao L. Comparative genomic analysis reveals occurrence of genetic recombination in virulent Cryptosporidium hominis subtypes and telomeric gene duplications in Cryptosporidium parvum. BMC Genomics. 2015;16:320

12. Liu S, Roellig DM, Guo Y, Li N, Frace MA, Tang K, Zhang L, Feng Y, Xiao L. Evolution of mitosome metabolism and invasion-related proteins in Cryptosporidium. BMC Genomics. 2016;17(1):1006.

13. Feng Y, Li N, Roellig DM, Kelley A, Liu G, Amer S, Tang K, Zhang L, Xiao L. Comparative genomic analysis of the Ild subtype family of Cryptosporidium parvum. Int J Parasitol. 2017:47(5):281-90.

14. Hunter CA, Sibley LD. Modulation of innate immunity by Toxoplasma gondii virulence effectors. Nat Rev Microbiol. 2012;10(11):766-78.

15. Bouzid M, Hunter PR, Chalmers RM, Tyler KM. Cryptosporidium pathogenicity and virulence. Clin Microbiol Rev. 2013;26(1):115-34.

16. Swapna LS, Parkinson J. Genomics of apicomplexan parasites. Crit Rev Biochem Mol Biol. 2017;52(3):254-73.

17. Khan A, Shaik JS, Grigg ME. Genomics and molecular epidemiology of Cryptosporidium species. Acta Trop. 2018;184:1-14.

18. Abrahamsen MS, Templeton TJ, Enomoto S, Abrahante JE, Zhu G, Lancto CA Deng M, Liu C, Widmer G, Tzipori S, et al. Complete genome sequence of the apicomplexan, Cryptosporidium parvum. Science. 2004;304(5669):441-5.

19. Xu P, Widmer G, Wang YP, Ozaki LS, Alves JM, Serrano MG, Puiu D, Manque $P$, Akiyoshi D, Mackey AJ, et al. The genome of Cryptosporidium hominis. Nature. 2004:431(7012):1107-12.

20. Ifeonu OO, Chibucos MC, Orvis J, Su Q, Elwin K, Guo F, Zhang H, Xiao L, Sun $\mathrm{M}$, Chalmers RM, et al. Annotated draft genome sequences of three species of Cryptosporidium: Cryptosporidium meleagridis isolate UKMEL1, C. baileyi 
isolate TAMU-09Q1 and C. hominis isolates TU502_2012 and UKH1. Pathog Dis. 2016;74(7):415-9.

21. Putignani L, Possenti A, Cherchi S, Pozio E, Crisanti A, Spano F. The thrombospondin-related protein CpMIC1 (CpTSP8) belongs to the repertoire of micronemal proteins of Cryptosporidium parvum. Mol Biochem Parasitol. 2008;157(1):98-101.

22. Sanderson SJ, Xia D, Prieto H, Yates J, Heiges M, Kissinger JC, Bromley E, Lal $\mathrm{K}$, Sinden $\mathrm{RE}$, Tomley $\mathrm{F}$, et al. Determining the protein repertoire of Cryptosporidium parvum sporozoites. Proteomics. 2008;8(7):1398-414.

23. Mauzy MJ, Enomoto S, Lancto CA, Abrahamsen MS, Rutherford MS. The Cryptosporidium parvum transcriptome during in vitro development. PLoS One. 2012;7(3):e31715.

24. Samuelson J, Robbins PW. Effects of N-glycan precursor length diversity on quality control of protein folding and on protein glycosylation. Semin Cell Dev Biol. 2015;41:121-8.

25. Blake DP. Eimeria genomics: where are we now and where are we going? Vet Parasitol. 2015;212(1-2):68-74.

26. Rutledge GG, Bohme U, Sanders M, Reid AJ, Cotton JA, Maiga-Ascofare O, Djimde AA, Apinjoh TO, Amenga-Etego L, Manske M, et al. Plasmodium malariae and $P$. ovale genomes provide insights into malaria parasite evolution. Nature. 2017;542(7639):101-4

27. Yamagishi J, Asada M, Hakimi H, Tanaka TQ, Sugimoto C, Kawazu SI. Wholegenome assembly of Babesia ovata and comparative genomics between closely related pathogens. BMC Genomics. 2017;18(1):832.

28. O'Connor RM, Burns PB, Ha-Ngoc T, Scarpato K, Khan W, Kang G, Ward H. Polymorphic mucin antigens CpMuc4 and CpMuc5 are integral to Cryptosporidium parvum infection in vitro. Eukaryot Cell. 2009;8(4):461-9.

29. Lorenzi H, Khan A, Behnke MS, Namasivayam S, Swapna LS, Hadjithomas M, Karamycheva S, Pinney D, Brunk BP, Ajioka JW, et al. Local admixture of amplified and diversified secreted pathogenesis determinants shapes mosaic Toxoplasma gondii genomes. Nat Commun. 2016;7:10147.

30. Mazurie AJ, Alves JM, Ozaki LS, Zhou S, Schwartz DC, Buck GA. Comparative genomics of Cryptosporidium. Int J Genomics. 2013;2013:832756.

31. Isaza JP, Galvan AL, Polanco V, Huang B, Matveyev AV, Serrano MG, Manque $P$, Buck GA, Alzate JF. Revisiting the reference genomes of human pathogenic Cryptosporidium species: reannotation of C. parvum lowa and a new C. hominis reference. Sci Rep. 2015;5:16324.

32. Zapata F, Perkins ME, Riojas YA, Wu TW, Le Blancq SM. The Cryptosporidium parvum ABC protein family. Mol Biochem Parasitol. 2002;120(1):157-61.

33. Widmer G, Lee Y, Hunt P, Martinelli A, Tolkoff M, Bodi K. Comparative genome analysis of two Cryptosporidium parvum isolates with different host range. Infect Genet Evol. 2012;12(6):1213-21.

34. Xiao LH, Escalante L, Yang CF, Sulaiman I, Escalante AA, Montali RJ, Fayer R, Lal AA. Phylogenetic analysis of Cryptosporidium parasites based on the small-subunit rRNA gene locus. Appl Environ Microb. 1999;65(4):1578-83.

35. Guo Y, Li N, Lysen C, Frace M, Tang K, Sammons S, Roellig DM, Feng Y, Xiao L. Isolation and enrichment of Cryptosporidium DNA and verification of DNA purity for whole-genome sequencing. J Clin Microbiol. 2015;53(2):641-7.

36. Darling AE, Mau B, Perna NT. Progressive Mauve: multiple genome alignment with gene gain, loss and rearrangement. PLoS One. 2010;5(6): e11147.

37. Krzywinski M, Schein J, Birol I, Connors J, Gascoyne R, Horsman D, Jones SJ, Marra MA. Circos: an information aesthetic for comparative genomics. Genome Res. 2009;19(9):1639-45.

38. Stanke M, Steinkamp R, Waack S, Morgenstern B. AUGUSTUS: a web server for gene finding in eukaryotes. Nucleic Acids Res. 2004;32(Web Server issue): W309-12.

39. Parra G, Blanco E, Guigo R. GenelD in drosophila. Genome Res. 2000;10(4): $511-5$.

40. Lomsadze A, Ter-Hovhannisyan V, Chernoff YO, Borodovsky M. Gene identification in novel eukaryotic genomes by self-training algorithm. Nucleic Acids Res. 2005;33(20):6494-506.

41. Haas BJ, Salzberg SL, Zhu W, Pertea M, Allen JE, Orvis J, White O, Buell CR, Wortman JR. Automated eukaryotic gene structure annotation using EVidenceModeler and the program to assemble spliced alignments. Genome Biol. 2008;9(1):R7.

42. Altschul SF, Gish W, Miller W, Myers EW, Lipman DJ. Basic local alignment search tool. J Mol Biol. 1990;215(3):403-10.

43. Petersen TN, Brunak S, von Heijne G, Nielsen H. SignalP 4.0: discriminating signal peptides from transmembrane regions. Nat Methods. 2011;8(10):785-6.
44. Krogh A, Larsson B, von Heijne G, Sonnhammer EL. Predicting transmembrane protein topology with a hidden Markov model: application to complete genomes. J Mol Biol. 2001;305(3):567-80.

45. Fankhauser N, Maser P. Identification of GPI anchor attachment signals by a Kohonen self-organizing map. Bioinformatics. 2005;21(9):1846-52.

46. Moriya Y, Itoh M, Okuda S, Yoshizawa AC, Kanehisa M. KAAS: an automatic genome annotation and pathway reconstruction server. Nucleic Acids Res. 2007;35(Web Server issue):W182-5.

47. Finn RD, Bateman A, Clements J, Coggill P, Eberhardt RY, Eddy SR, Heger A, Hetherington $\mathrm{K}$, Holm L, Mistry J, et al. Pfam: the protein families database. Nucleic Acids Res. 2014:42(Database issue):D222-30.

48. Shanmugasundram A, Gonzalez-Galarza FF, Wastling JM, Vasieva O, Jones AR. Library of Apicomplexan metabolic pathways: a manually curated database for metabolic pathways of apicomplexan parasites. Nucleic Acids Res. 2013;41(Database issue):D706-13.

49. Li L, Stoeckert CJ Jr, Roos DS. OrthoMCL: identification of ortholog groups for eukaryotic genomes. Genome Res. 2003;13(9):2178-89.

50. Wang D, Zhang Y, Zhang Z, Zhu J, Yu J. KaKs_Calculator 2.0: a toolkit incorporating gamma-series methods and sliding window strategies. Genomics Proteomics Bioinformatics. 2010;8(1):77-80.

51. Edgar RC. MUSCLE: multiple sequence alignment with high accuracy and high throughput. Nucleic Acids Res. 2004;32(5):1792-7.

52. Castresana J. Selection of conserved blocks from multiple alignments for their use in phylogenetic analysis. Mol Biol Evol. 2000;17(4):540-52.

53. Stamatakis A, Ludwig T, Meier H. RAxML-III: a fast program for maximum likelihood-based inference of large phylogenetic trees. Bioinformatics. 2005; 21(4):456-63.
Ready to submit your research? Choose BMC and benefit from:
- fast, convenient online submission
- thorough peer review by experienced researchers in your field
- rapid publication on acceptance
- support for research data, including large and complex data types
- gold Open Access which fosters wider collaboration and increased citations
- maximum visibility for your research: over $100 \mathrm{M}$ website views per year
At BMC, research is always in progress.
Learn more biomedcentral.com/submissions 